\title{
Radial flow velocity profiles of a yield stress fluid between smooth parallel disks
}

\author{
Tafadzwa John Shamu ${ }^{1}$ (1) • Liangchao Zou ${ }^{2} \cdot$ Reinhardt Kotzé $^{3} \cdot$ Johan Wiklund ${ }^{3}$ • Ulf Håkansson ${ }^{1,4}$
}

Received: 23 April 2019 / Revised: 19 February 2020 / Accepted: 19 February 2020 / Published online: 7 March 2020

(C) The Author(s) 2020

\begin{abstract}
In rock grouting, idealized 2D-radial laminar flow of yield stress fluids (YSF) is a fundamental flow configuration that is used for cement grout spread estimation. A limited amount of works have presented analytical and numerical solutions on the radial velocity profiles between parallel disks. However, to the best of our knowledge, there has been no experimental work that has presented measured velocity profiles for this geometry. In this paper, we present velocity profiles of Carbopol (a simple YSF), measured by pulsed ultrasound velocimetry within a radial flow model. We describe the design of the physical model and then present the measured velocity profiles while highlighting the plug-flow region and slip effects observed for three different apertures and volumetric flow rates. Although the measured velocity profiles exhibited wall slip, there was a reasonably good agreement with the analytical solution. We then discuss the major implications of our work on radial flow.
\end{abstract}

Keywords 2D-radial flow $\cdot$ Plug-flow region · Velocity profile $\cdot$ Ultrasound velocimetry $\cdot$ Slip $\cdot$ Yield stress fluid (YSF) . Cement-based grouts

\section{Introduction}

Cement-based grouting of rock fractures to minimize water inflow into underground constructions, e.g., tunnels, is a common practice, especially in Scandinavia (Håkansson et al. 1992; Fransson 2001; Gustafson and Stille 2005; Gustafson et al. 2013; Axelsson et al. 2009; El Tani 2012; Rahman et al. 2017; Zou et al. 2018, 2019). The effectiveness of the grouting process depends largely on fracture geometry, grouting design and execution, penetrability, and rheological properties of the cement grouts that are used (Zou et al. 2019; Håkansson 1993; Draganović and Stille 2014; Stille 2015; Fransson et al. 2016; Nejad Ghafar 2017).

Tafadzwa John Shamu

jshamu@kth.se

1 Division of Soil and Rock Mechanics, KTH Royal Institute of Technology, Stockholm, Sweden

2 Division of Resources, Energy and Infrastructure, Royal Institute of Technology, Stockholm, Sweden

3 Incipientus Ultrasound Flow Technologies AB, Gothenburg, Sweden

4 Skanska Sweden AB, Stockholm, Sweden
To model the complex flow process of cement grouts in rock fractures, they are often regarded as simple yield stress fluids (YSF), i.e., without thixotropy (Ovarlez et al. 2013) and rheological constitutive models such as the Bingham model have been widely used to describe the flow. The Bingham model defines a yield stress component $\tau_{0}$, representing the minimum stress required to initiate and maintain flow and $\mu_{B}$ the grout's viscosity (Balmforth et al. 2014). As an alternative to the two parameter Bingham model, being a gross oversimplification, other flow models such as the Herschel-Bulkley (HB) (i.e., $\tau=\tau_{0}+k \dot{\gamma}^{n}$ where $\tau$ is the shear stress, $\dot{\gamma}$ is the shear rates, $\tau_{0}$ is the yield stress, $k$ is the consistency coefficient, and $n$ is the flow index) are known to better describe the shear thinning behavior of cement grouts, particularly in the lower shear rate range $(<\sim 101 / \mathrm{s})$ (Coussot et al. 2006; Coussot 2017; Bonn et al. 2017).

For design purposes, rock fractures are often idealized by the use of geometries such as one-dimensional (1D) channels and two-dimensional (2D) radial flow between parallel disks (Lipscomb and Denn 1984; Stille 2015; Zou et al. 2018). Analytical and numerical solutions to problems involving YSF flow in pipes and channels have been described extensively in the literature (Coussot 2014; Balmforth et al. 2014; Bonn et al. 2017). For instance, Chhabra and Richardson (1999) and Coussot (2014) describe several analytical 
solutions for Bingham and Herschel-Bulkley fluids in simple geometries such as pipe flow, pointing out the main differences with experimental observations and the limitations associated with their use in practical applications. For cement grouts, analytical solutions have been derived using the Bingham model to describe flow in air- or water-filled channels with rectangular cross sections and pipes, thereby simplifying analyses under similar flow conditions (Hässler 1991; Håkansson 1993). At present, most propagation models for cement grouting of rock fractures are based on these analytical solutions in such idealized geometrical conditions (Gustafson et al. 2013), e.g., developed propagation models for Bingham fluids in 1D channels, pipes, and between parallel 2D disks. However, these analytical solutions are all based on the lubrication assumption, i.e., simplification of the equation of motion based on the relatively smaller aperture compared to length in the flow direction (Ovarlez and Hormozi 2018). The validity of such solutions in 2D radial flow needs to be ascertained by comparing with experimentally measured velocity profiles.

A large number of experimental studies using imaging and velocimetry measurement techniques, e.g., magnetic resonance imaging (MRI), particle image velocimetry (PIV), and ultrasound velocity profiling (UVP), have shown the shape of the velocity profiles that develop in simple geometries (McCarthy et al. 1997; Wunderlich and Brunn 1999; Dogan et al. 2005; Pfund et al. 2006; Birkhofer 2007; Powell 2008; Wiklund et al. 2007; Kotze et al. 2012; Rahman et al. 2017). In the case of radial flow of YSFs between stationary parallel plates, where the velocity distribution across the aperture varies considerably along the radial direction, analytical solutions for Bingham and power-law fluids have been developed (El Tani 2012; Lipscomb and Denn 1984; Dai and Byron Bird 1981; Na and Hansen 1967), with the recent work by Guo et al. (2017) having presented an exact solution to the Navier-Stokes equation. Nevertheless, only a few experiments have been presented for radial flow, mostly focusing on flow rate measurement and pressure distribution along the radial direction (Savage 1964; Laurencena and Williams 1974; Wallner 1977; Majidi et al. 2010; Mohammed 2015; Funehag and Thörn 2018). Some of the earliest references to radial flow experiments describe tests carried out with several non-Newtonian fluids including a simple model YSF in the form of Carbopol (Laurencena and Williams 1974). Tracer particles used in their work strongly suggested the presence of flow instabilities and secondary flow for predominantly viscoelastic fluids (i.e., concentrated Carbopol gels), compared to purely viscous fluids (Laurencena and Williams 1974). The work by Wallner (1977) was one of the first experimental studies related to grouting with actual cements, stabilized with bentonite to prevent sedimentation. Within that study, radial grout spread rates were compared to theoretical predictions assuming the Bingham model (Wallner 1977).
More recently, experimental and numerical investigations have been carried out in radial flow configurations (Majidi et al. 2010; Funehag and Thörn 2018). In the work by Majidi et al. (2010), Xanthan gum was used as the test fluid; and the measured pressure distributions agreed quite well with analytical predictions that used yield-power-law fluid parameters to describe the rheology of the test fluids. The main discrepancies were related to data at high flow rates where the set aperture increased due to buildup of internal pressures. The experimental work by Mohammed (2015) and Funehag and Thörn (2018) was mainly targeted towards the measurement of penetration lengths and times, assuming the Bingham model for the grouts. In the test setups described by Mohammed (2015) and Funehag and Thörn (2018), the flow areas were formed by parallel acrylic plastic (plexiglass) material with bolts (fasteners) that invaded the flow aperture. In such flow configurations, the fasteners might then disturb the underlying flow under study.

To the best of our knowledge, there has been no experimental work in the literature showing the nature of velocity profiles within the radial flow geometry for non-thixotropic fluids with a yield stress component. To fill in this knowledge gap, we therefore present for the first time, time-averaged velocity profiles of a simple YSF in the form of Carbopol ${ }^{\circledR}$ NF 980 as measured by UVP within a radial flow model. Carbopol gel prepared from carbomer powder (cross-linked polymer of acrylic acid) has been increasingly used as a simple YSF model fluid in flow experiments, since it exhibits negligible thixotropic effects (i.e., rheological hysteresis) when prepared appropriately (Di Giuseppe et al. 2015; Bonn et al. 2017; Dinkgreve et al. 2018). Depending on the preparation procedure and the type of carbomer powder used to prepare the gel, thixotropic effects can however be observed (Di Giuseppe et al. 2015; Dinkgreve et al. 2017, 2018). To address the objectives of this work, we present the design and assembly of the physical radial model that has an uninterrupted flow area. In addition, we describe the ultrasound sensor characterization and the preparation of the Carbopol gels. We then present the measured velocity profiles, highlighting the plug-flow region and slip effects that were observed under different flow conditions, i.e., three disk apertures (spacings) and three volumetric flow rates. In conclusion, we discuss the main differences between idealized YSF radial flow compared to our current observations.

\section{Materials and experimental method}

\section{Materials and preparation}

Carbopol gel prepared from carbomer powder (Carbopol® NF 980 from Lubrizol, Belgium) was used as the model YSF for our tests. Carbopol gels are widely used as model 
fluids in flow experiments since they are known as simple YSF that exhibit negligible thixotropy when prepared accordingly (Dinkgreve et al. 2018; Di Giuseppe et al. 2015; Roberts and Barnes 2001; Dinkgreve et al. 2017). Several studies have shown that the two-step preparation process of Carbopol gels, i.e., dispersion in water + neutralization with a suitable base, needs to be carried out consistently (same mixing protocol, times, etc.) in order to achieve reasonably similar batches (Divoux et al. 2011; Kelessidis and Hatzistamou 2011; Di Giuseppe et al. 2015). During the neutralization stage, high shear mixing (intense stirring) has been shown to be one of the main causes for rheological hysteresis, since in this way, the polymer chains are broken up into much smaller fragments (Dinkgreve et al. 2018). To prepare each of our Carbopol batches, a weighed amount of carbomer powder $(0.1 \mathrm{wt} \%$ of the final dispersion) was dispersed in $28 \mathrm{~kg}$ of distilled water (supplied by Würth) at room temperature $\sim 22^{\circ} \mathrm{C}$. A Silverson AX5 high shear mixer was then used for preparing the dispersion at a maximum of $\sim 1000 \mathrm{rpm}$ for $\sim 25 \mathrm{~min}$. The powder was added in small amounts while stirring with the mixer. The dispersion was then left to rest for about $\sim 1 \mathrm{~h}$ allowing for increased hydration. After the rest period, the dispersion was seeded with ( $0.25 \mathrm{wt} \%$ of the dispersion) copolyamide acoustic reflector particles with a size range $\sim 80-200 \mu \mathrm{m}$ and density $1.07 \mathrm{~g} / \mathrm{cm}^{3}$ (supplied by MET-FLOW SA), in order to facilitate the measurement of velocity profiles with the ultrasound velocity profiling (UVP) method. A small amount of coloring agent Spectracol Patent Blue V (supplied by Sensient Colors GmbH Germany) at $0.005 \mathrm{wt} \%$ of the dispersion mass was added so that the flow of the gel could be visualized through the acrylic glass (plexiglass) disks. The last step in the fluid preparation protocol involved neutralization of the dispersion with an $18 \mathrm{wt} \%$ solution of sodium hydroxide $(\mathrm{NaOH})$. The $\mathrm{NaOH}$ was added dropwise with a pipette to reach a final $\mathrm{pH}$ of $\sim 6.5-7.5$ while stirring gently at a maximum of $\sim 100 \mathrm{rpm}$, using a mixer (RW 20, supplied by IKA) with a ribbon rotor head.

\section{Rheological test equipment and procedure}

The rheological test instrument used was a TA AR-2000ex rheometer with a Couette-type geometry. The geometry used was made up of a vane (diameter $=15 \mathrm{~mm}$, height $=38 \mathrm{~mm}$ ) and a smooth stainless steel cup (diameter $=30 \mathrm{~mm}$ ). Flow sweeps in controlled shear rate (CSR) mode were then carried out (Nguyen 1992; Barnes and Nguyen 2001).

Procedure: A CSR logarithmic sweep was then applied ranging from 0.001 to $80 \mathrm{1} / \mathrm{s}$ for the up-curve and 80 to $0.001 \mathrm{l} / \mathrm{s}$ for the down-curve, with 10 points per decade. For each measuring point, the shear rate was held constant for a maximum of $\sim 30 \mathrm{~s}$ to check for hysteresis while allowing for a steady-state condition. The rheological flow curve representative of our Carbopol gels $(0.1 \mathrm{wt} \%)$ is shown in Fig. 3.

\section{Ultrasound velocity profiling (UVP)}

To acquire radial velocity profiles, the Incipientus Flow Visualizer (IFV) system together with a $5 \mathrm{MHz}$ noninvasive ultrasound sensor (supplied by Incipientus AB, Sweden) was used. The Incipientus ultrasound system is also capable of inline rheometric measurements when the UVP technique is combined with pressure difference (PD) measurements (UVP + PD). The Incipientus technology and system has been developed through several years of research on in-line rheological measurements of complex industrial fluids, e.g., food products, cement grouts, and mineral suspensions (Wiklund et al. 2007; Ricci et al. 2010, 2017; Kotze et al. 2012; Berta et al. 2016). However, we mention this briefly as this is beyond the scope of the current study.

The UVP method for measuring velocity profiles is based on the detection of frequency shifts between subsequent ultrasound echo signals reflected from particles flowing at certain distances/depths from the ultrasound sensor. The accuracy of velocimetry measurements is mainly dependent on accurate values of the sound velocity $c$ and Doppler angle $\theta$ (i.e., the angle of propagation of the ultrasound beam, also determining the measurement axis) (Takeda 1999, 2012; Shamu et al. 2016). The main equation that is used to calculate the individual velocities $v_{i}$ that contribute to the $1 \mathrm{D}$ velocity profile is given as:

$v_{i}=c f_{d_{i}} / 2 f_{0} \cos \theta$,

where $v_{i}$ is the mean velocity for particles flowing at a certain axial distance (gate), $f_{0}$ is the central ultrasound transmission frequency, $c$ is the velocity of sound, $f_{d_{i}}$ is the Doppler shift frequency for particles flowing at a certain distance (gate), and $\theta$ is the Doppler angle. Specific details of pulsed-ultrasound electronics used to transmit and receive the ultrasound signals as well as the signal processing algorithms to calculate the velocities from the received echo data have been described extensively in the literature (Barber et al. 1985; Ricci et al. 2006; Wiklund et al. 2007; Ricci et al. 2012; Kotze et al. 2012; Ricci and Meacci 2018). Analyses and measurements show that the error from the Doppler angle has a more significant contribution towards the total velocity error; thus, it is crucial to characterize the beam propagation angle through acoustic tests (Takeda 2012; Shamu et al. 2016).

\section{Measurement procedure: sound velocity}

The velocity of sound of the Carbopol gels was measured in an off-line sound velocity measurement setup (a cylindrical cell) by averaging the time of flight (TOF) of 12 repeated bursts of pulsed ultrasound at $f_{0}=5 \mathrm{MHz}, 2$ cycles per pulse (Wiklund et al. 2007). The distance between the ultrasound sensor face and the reflecting wall of the cell in the sound 
velocity measurement setup was $\sim 31 \mathrm{~mm}$. The average sound velocity for different Carbopol samples was determined to be $\sim 1490-1510 \mathrm{~m} / \mathrm{s}$ at a temperature of $\sim 19{ }^{\circ} \mathrm{C}$.

\section{Ultrasound sensor acoustic characterization}

In order to determine the ultrasound beam propagation angle after the plexiglass wall interface, we carried out acoustic characterization tests using a needle hydrophone setup. A 5$\mathrm{mm}$-thick plexiglass sheet with the same acoustic properties as the radial flow model wall was attached to the face of the $5 \mathrm{MHz}$ ultrasound sensor. The same oil-based couplant that was used within the slot of the radial model was also used during the acoustic test. The test configuration and method used for the acoustic scanning were similar to that from our previous tests as described by Shamu et al. (2016). A 1-mm needle hydrophone with an 8-dB preamplifier (supplied by precision-acoustics, UK) was used to measure the peak voltages, in a rectangular horizontal plane (grid) along the sensor's plane of maximum acoustic energy (Shamu et al. 2016). For the present acoustic test, an Incipientus UVP system was used to continuously transmit preprogrammed pulses to the ultrasound sensor. The pulse transmission settings were $5 \mathrm{MHz}$ central frequency, at 2 cycles per pulse, $120 \mathrm{~V}$ peak-to-peak voltage, and a linear gain setting of $20 \mathrm{~dB}$. Deionized water (Milli-Q ${ }^{\circledR}$ ) at $\sim 19^{\circ} \mathrm{C}$ was used during the acoustic characterization. The output from the acoustic characterization test in the form of measured peak-to-peak voltages at different spatial points (1-mm grid resolution) is then plotted as a colormap to show the beam propagation angle. The Doppler angle was measured as $\sim 70.23{ }^{\circ} \mathrm{C}$ (Fig. 1c). This Doppler angle was used as a good approximation to that in the actual setup since the magnitudes of the velocity of sound in Carbopol and deionized water are close.

\section{Radial model design and test protocol}

A stainless steel-framed radial flow experimental model was designed and manufactured for the radial flow tests. The model is made up of two smooth parallel acrylic plastic (from Plexiglas $($ ) disks each with a diameter of $1 \mathrm{~m}$ and a thickness of $25 \mathrm{~mm}$ (Fig. 2). The inlet pipe in the center of the radial plates is connected to a pipe of diameter $20 \mathrm{~mm}$ and height of $80 \mathrm{~cm}$. The central inlet edges on the top disk are smoothed to allow for a smooth entry condition into the flow area. The aperture (disk spacing), which is crucial to the radial flow experiments, is implemented by means of a variable metallic spacer configuration. These spacers ( 8 in total) have three heights, allowing for an adjustable disk spacing, creating a clearance region wherein the fluid flows. The top plexiglass disk is reinforced by a stainless steel spoke frame, which serves as a brace support against disk bending, while the fluid is being pumped. Together the spoke frame and spacer design at the periphery of the circular disks ensures that the desired flow area and aperture are achieved, without any physical disturbance; an initial design had an interrupted flow area, i.e., with invasive fastening bolts through both disks. Furthermore, the bolts and frame members are dimensioned to resist uplift pressure from the flowing fluid. In this way, a design with an equally constant aperture for our tests is achieved. Likewise, the bottom disk is supported by steel frames from the base steel structure. A piston rotor pump
Fig. 1 a Top view schematic of the acoustic map showing the horizontal scanning grid. b Image of the acoustic characterization test setup. c Acoustic color map showing the measured ultrasound beam propagation angle (Doppler angle, $\theta$ ) a

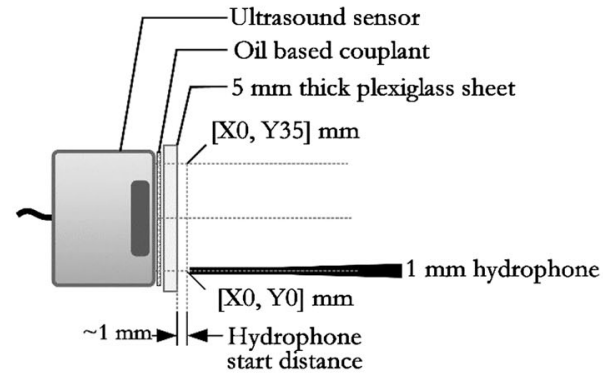

b

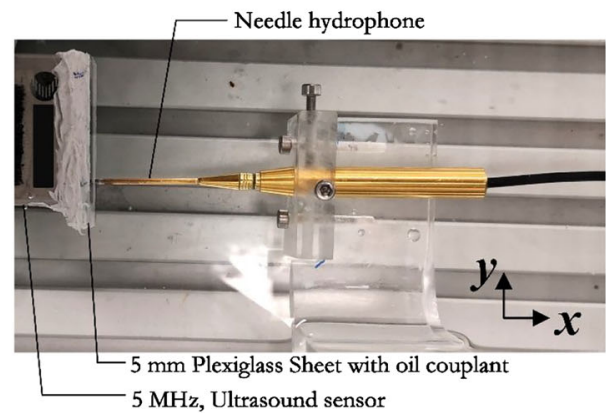

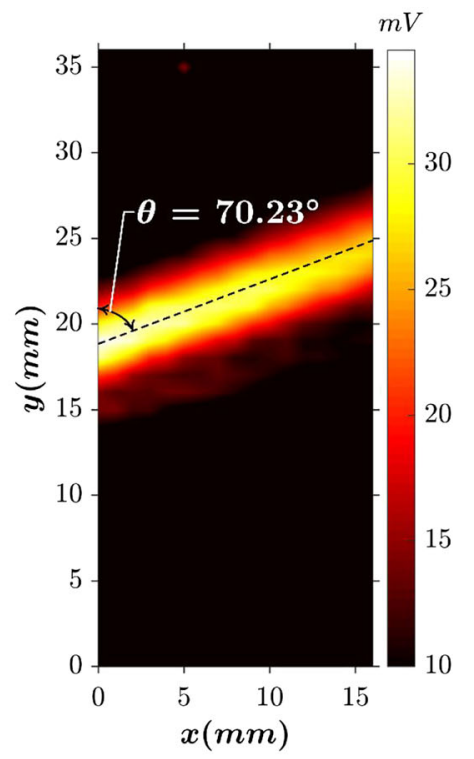


Fig. 2 a Schematic of the radial flow model components. b Cross section view of the ultrasound sensor and linear axis setup along the radial measurement length (slot). Images of $\mathbf{c}$ ultrasound sensor within the slot along the radial length. $\mathbf{d}$ Image showing fixture with spacer and spoke frame to set the aperture a

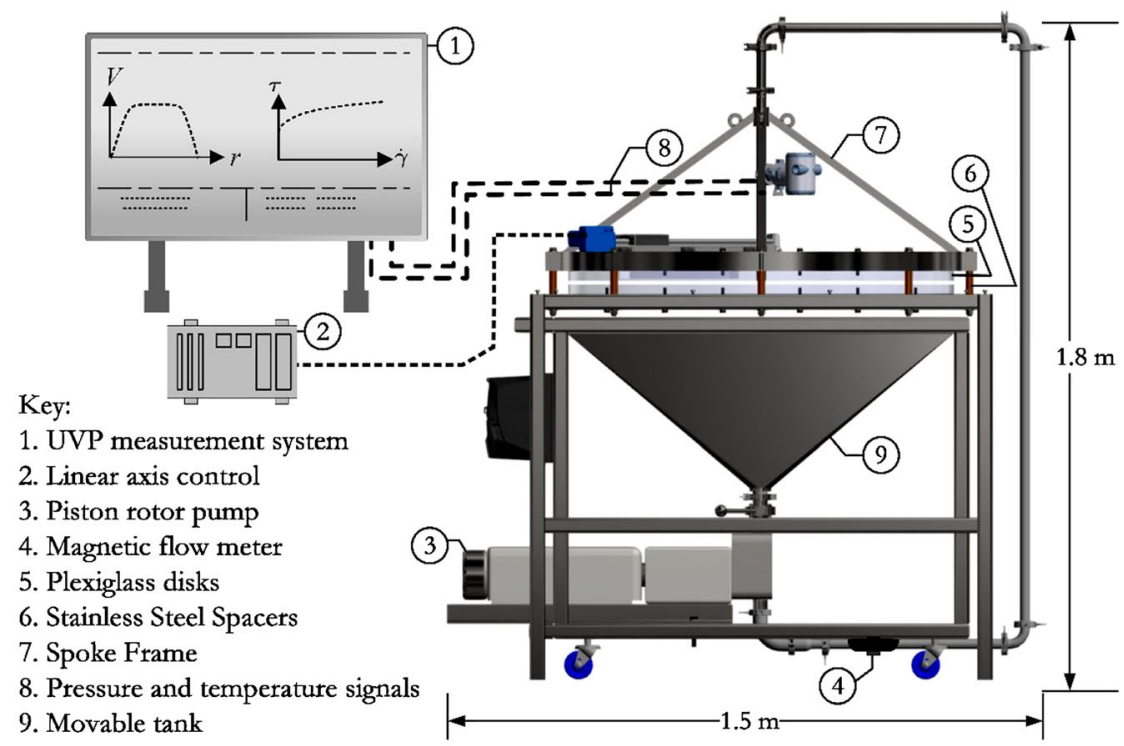

b

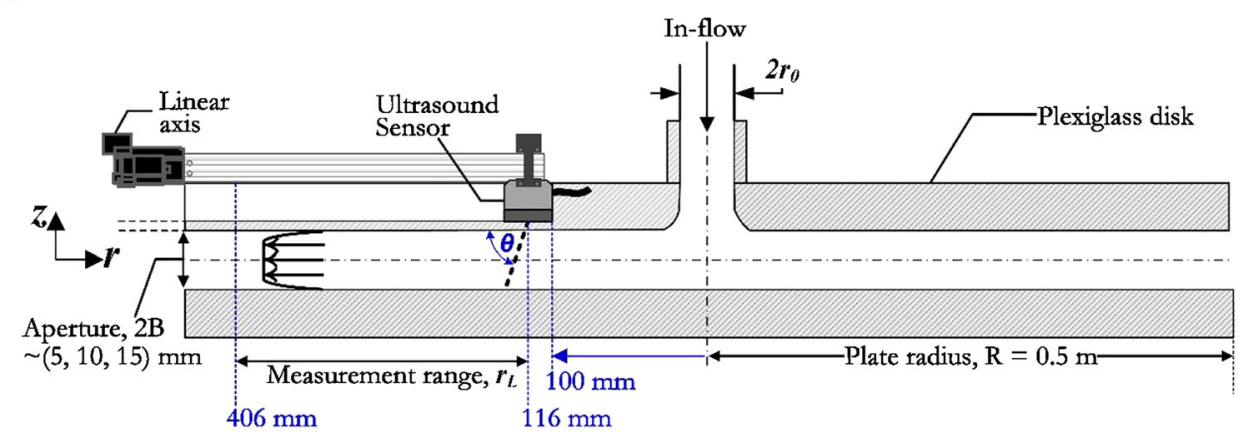

c
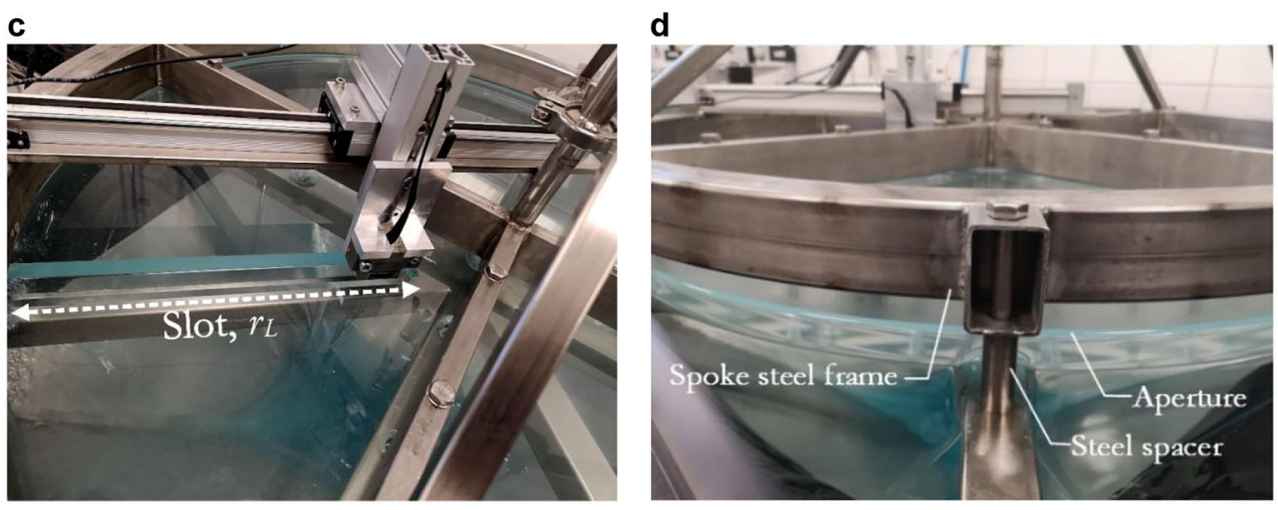

(supplied by Colly FlowTech AB, Sweden) was selected, since it pumps with minimal shear of the fluid and offers fine control over the flow rate with the variable frequency drive. Temperature is measured by a PT100 temperature device, and the volumetric flow rate is measured by a magnetic flow meter (Discomag DMI 6531, Endress + Hausser) placed at the outlet of the pump (Fig. 2).

The ultrasound sensor is attached to a computer-controlled linear axis that is fixed on the top plexiglass disk to track the radial position. The noninvasive sensor is then connected to the IFV instrument and moved to different radial locations by the motorized linear axis (Isel LEZ1 supplied by Solectro AB, Sweden), along a rectangular slot of depth $20 \mathrm{~mm}$ and width $34 \mathrm{~mm}$ that is machined into the top disk. The slot resulted in a thinner plexiglass wall of thickness $5 \mathrm{~mm}$, allowing for effective ultrasound propagation through the disk wall into the test fluid. The assembly of components and steel framework was then carried out by Mekpart AB, Sweden. A computer-aided design (CAD) model of the physical model designed within the Autodesk Inventor ${ }^{\circledR}$ package was used to simulate and 
check the vertical displacement (aperture increase) under uniformly applied uplift pressures on both top and bottom disks of up to $\sim 13 \mathrm{kPa}$; from this, we estimate only a marginal displacement in the smallest aperture used $(5 \mathrm{~mm})$. Thus, we consider all the experimental radial flows described in this paper to be carried out under constant aperture conditions (see Appendix 2).

\section{Tests protocol: velocity profile measurements}

For each test, a single batch of the Carbopol fluid is poured into the movable tank at room temperature $\left(\sim 18.5-20{ }^{\circ} \mathrm{C}\right)$. The fluid is then circulated within the tank for about $~$ 2 min, allowing for homogenization and to attain a steady flow rate before starting the velocity profile measurements. Three flow rates based on the pump's maximum deliverable flow rate are used: $\mathrm{Q} 1=\sim 28 \mathrm{l} / \mathrm{min}, \mathrm{Q} 2=\sim 40 \mathrm{l} / \mathrm{min}$, and $\mathrm{Q} 3=58 \mathrm{l} / \mathrm{min}$, as measured by the magnetic flow meter. Velocity profiles at 17 different locations along the slot are then acquired at a constant controlled flow rate. The radial locations for velocity profile measurements are between 116 and $406 \mathrm{~mm}$ at $20 \mathrm{~mm}$ intervals and the last two measurements at $5 \mathrm{~mm}$ intervals (Fig. 2b). The aperture is varied ( $5 \mathrm{~mm}, 10 \mathrm{~mm}, 15 \mathrm{~mm}$ ) by changing the steel spacers; thus, a total of 51 profiles were measured per gap. A maximum time of $\sim 2 \mathrm{~min}$ is needed to acquire a single mean velocity profile (averaged from 255 profiles). The test conditions and UVP settings are summarized in Table 1.

\section{Method for determining plug region}

For the analysis of velocity profiles shown in this study, we present an algorithm to approximate the extent of the plugflow region. The position of the plug ( $z_{p}$, approximate yield point along the aperture distance) is estimated using a cumulative sum (CUSUM)-based algorithm, as implemented within the MATLAB $®$ environment (Grigg et al. 2003). In our case, the CUSUM-based procedure to detect the plug was as follows:

(i) Firstly, normalize the velocity profile (velocity $\left(V_{z} /\right.$ $\left.V_{z} \max \right)$ and aperture distance $\left.(z / B)\right)$, and to the normalized profiles fit a smoothing spline to minimize the influence of local fluctuations within the plug region on the detection.

(ii) From the smoothing spline, the standard deviation $\sigma_{V}$ from $60 \%$ of the velocity points located in the region $[0 \leq z \leq 0.6(B)]$ is calculated as an approximation to the maximum expected fluctuations within the plug region (the 0.6 value is based on the extent of observable plug region from the normalized velocity profiles). A target median value $\widetilde{x}_{V}$ is then calculated from $25 \%$ of the velocity points, i.e., within a quarter of the half aperture $[0 \leq z \leq 0.25(B)]$, giving a reasonable approximation of the magnitude of the central plug velocity.

(iii) Using the CUSUM operation with inputs from (i) and (ii), the plug position is then determined at the point $z_{p}$ at which the velocity profile is 6 standard deviations $\left(6 \sigma_{V}\right)$ less than the target value $\left(\widetilde{x}_{V}\right)$.

\section{Experimental results}

\section{Flow curve measurement}

The flow curve data obtained from the controlled shear rate (CSR) flow sweeps, carried out on the Carbopol batches, show simple YSF behavior, i.e., with little or no rheological hysteresis (thixotropy), even at low shear rates. The flow curve is shown in linear-logarithmic format (Fig. 3). The first 2 to 3 points of the up-curve correspond to elastic startup
Table 1 UVP test parameters and test conditions for a $5 \mathrm{MHz}$ transducer measuring Carbopol $0.1 \mathrm{wt} \%$

\begin{tabular}{ll}
\hline Parameter & Value \\
\hline Ultrasound sensor central frequency, $f_{0}$ & $5 \mathrm{MHz}$ \\
Number of cycles per pulse & 2 \\
Number of pulse repetitions per pulse & 256 \\
Number of velocity profiles averaged & 255 \\
Gain setting (received signal) & $26 \mathrm{~dB}$ \\
Transmission voltage (TX) & $\sim 80 \mathrm{Vpp}$ \\
Velocity profile spatial resolution (with decimation), $\Delta z$ & $0.028 \mathrm{~mm}$ \\
Velocity of sound in Carbopol 0.1 wt\% & $\sim 1490-1510 \mathrm{~m} / \mathrm{s}$ \\
Velocity estimation method & Fast Fourier transform $(\mathrm{FFT})$ \\
Magnetic flow meter volume flow rate & $\mathrm{Q} 1=\sim 281 / \mathrm{min} ; \mathrm{Q} 2=\sim 40 \mathrm{l} / \mathrm{min} ; \mathrm{Q} 3=\sim 581 / \mathrm{min}$ \\
Doppler angle & $\sim 70.23^{\circ}$ \\
Disk apertures & $5 \mathrm{~mm} ; 10 \mathrm{~mm} ; 15 \mathrm{~mm}$
\end{tabular}




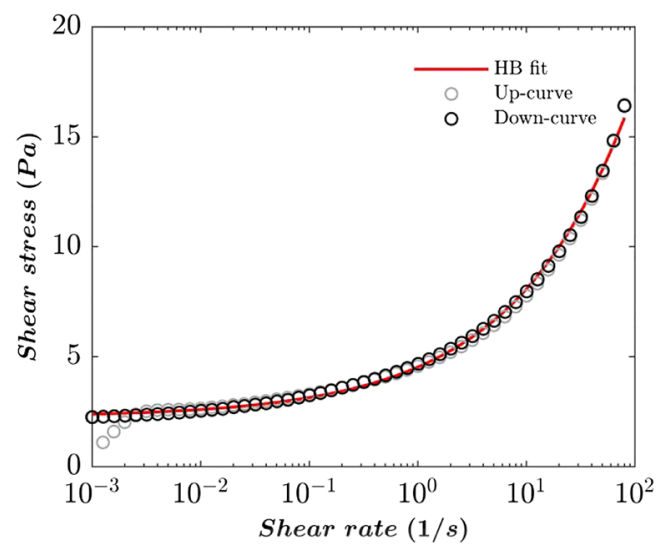

Fig. 3 Flow curve measurement of Carbopol-980 gel at $0.1 \%$ w/w. Herschel-Bulkley parameters from curve fitting were determined as $\tau_{0}=2.24 \mathrm{~Pa}, k=2.28 \mathrm{~Pa} . \mathrm{s}^{\mathrm{n}}$, and $n=0.4$

effects (Bonn et al. 2017). From the flow curve, we also show that the addition of the acoustic reflector particles plus a colorant powder did not alter the simple YSF behavior of the Carbopol gel since no unstable flow (s-type flow curve region associated with shear banding) was noted from the flow curve (Cheng 2003; Divoux et al. 2016). By fitting the Herschel-Bulkley (HB) model to the down-curve, the following parameters were obtained: $\tau_{0}=2.24 \mathrm{~Pa}, k=2.28 \mathrm{~Pa} . \mathrm{s}^{\mathrm{n}}$, and $n=0.4$. These HB parameters were also used as input to the constant flow rate analytical solution for radial flow (see Appendix 1).

\section{Volumetric flow rate measurements}

A comparison of the volumetric flow rates measured by the magnetic flow meter connected to the pump outflow at the bottom of the tank and those measured from the measured radial velocity profiles was carried out. Approximate flow rates $Q$ for a set of conditions (i.e., aperture, and flow rate set from the pump variable frequency drive (VFD)) were calculated from measured velocity profiles at different radial positions along the slot as follows:

$Q=V_{\text {mean }} 2 \pi r(2 B / \cos (90-\theta))$

where $V_{\text {mean }}$ is the average flow velocity from a velocity profile, $\theta$ is the Doppler angle defining the measurement axis, $B$ is half aperture (vertical disk spacing), and $r$ is the radial distance from the disks' center. The average radial flow rates from the velocity profiles and the flow meter agree quite well, but a larger difference was noted for the 5-mm gap. The magnetic flow meter readings (dashed gray line) compared to the velocity profile flow rates are presented with boxplots (median, Fig. 4). Firstly, the narrow spread represented by the boxplots may largely be explained by the local irregularities in the surface of the machined slot that tend to affect the wall positions (wall gates) in the measured velocity profile (Wiklund et al. 2007). Moreover, we point out that the impact of this wall gate uncertainty on the overall velocity profile and calculated flow rate reduces with increased aperture; thus, it is expected to have a larger difference for the smallest aperture. The wall uncertainty is mainly due to the overlapping of the finite sample volume at the fluid-wall interface and possibly the coupled effect of wall slip. As for the 5-mm aperture, it could be the case that there was a slight increase in the aperture due to increased pressure buildup.

As a reference to flow rate conditions throughout the paper, we will use the following as outlined in Table 1: Q1 $=\sim 28 \mathrm{l} /$ $\min , \mathrm{Q} 2=\sim 40 \mathrm{l} / \mathrm{min}$, and $\mathrm{Q} 3=\sim 58 \mathrm{l} / \mathrm{min}$.

\section{Velocity profile measurements}

Figure 5 shows a single velocity profile spectral image (Fig. 5a) and a mean velocity profile (Fig. 5b) for a measurement at $\sim 40 \mathrm{l} / \mathrm{min}, 316 \mathrm{~mm}$ and $15 \mathrm{~mm}$ aperture. The colored spectra highlight high intensity regions in the Doppler frequency power spectrum, which correspond to the calculated velocities (Fig. 5a). Although the measurement axis was oriented at an angle (Doppler angle $=70.23^{\circ}$ ) to the horizontal, to enable ultrasound velocimetry, we point out that there was no significant difference noted between theoretical profiles oriented at both $70.23^{\circ}$ and $90^{\circ}$. Thus, we assume symmetry across the aperture in the measured velocity profiles. In addition, the far-wall data (opposite to the ultrasound sensor) is affected by multiple reflections from the far wall as seen in the spectral image (i.e., bright spectra move towards maximum velocity between $\sim 12$ and $\sim$ $15 \mathrm{~mm}$ ). Therefore, we present velocity profiles across half the aperture, $B$. The error bars plotted on the mean velocity profile represent the velocity standard deviation at every distance point (gate) across the aperture (Fig. 5b). These deviations are representative of those in the velocity profiles we present in the rest of the paper.

\section{Sample volume overlap}

Velocity profiles measured using ultrasound velocimetry techniques often feature some distortion in the near wall that is seen as a slight flattening or reduced velocity gradient in the near-wall region (Fig. 5b, sample volume overlap). This distortion or flattening is due to the sample volume overlapping with the solid wall-fluid interface and has been reported in previous studies (Jorgensen and Garbini 1974; Wunderlich and Brunn 1999; Birkhofer 2007). The sample volume is described as the spatial region that the ultrasound pulse extends during its propagation from the ultrasound transducer surface, through the plexiglass walls and into the fluid under measurement. The dimensions of the sample volume are approximated from the pulse width, i.e., number of cycles in the ultrasound waveform. By considering a defined pulse shape for the 


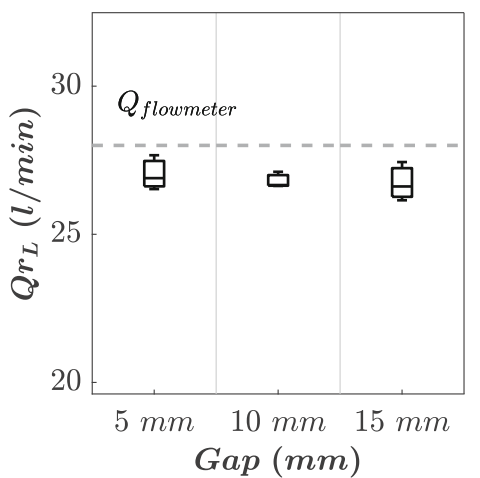

b

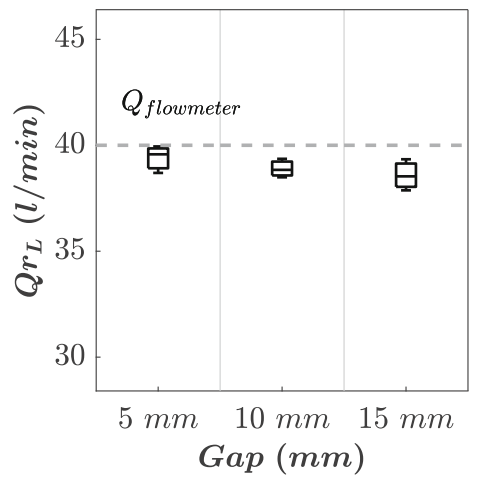

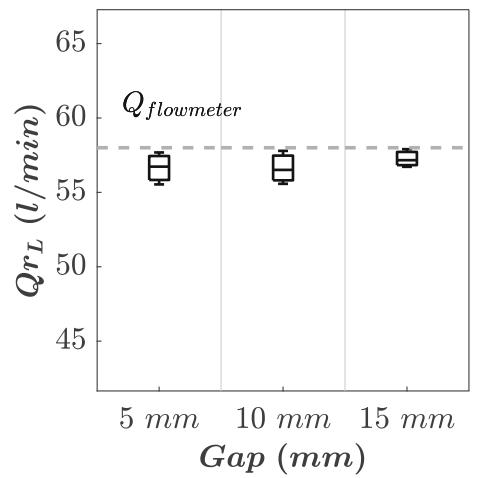

Fig. 4 Boxplots showing the volume flow rates measured from the velocity profiles at different radial positions. Each set of boxplots is from the 3 apertures with magnetic flow meter readings. a $\sim 28 \mathrm{l} / \mathrm{min}$. b $\sim 40 \mathrm{l} / \mathrm{min}$. c $58 \mathrm{l} / \mathrm{min}$

sample volume, the measured velocity profile is thus a convolution of the sample volume and the actual velocity profile of the fluid.

To correct for this distortion, deconvolution procedures have been developed, i.e., solving the integral equation for the true velocity profile which in one-dimensional form is $V_{w}=\int_{0}^{r} V_{t}(x) I(r-x) d x$ where $r$ is the distance along the ultrasound measurement path, $V_{w}$ is the normalized weighted average velocity, $V_{t}$ is the true velocity distribution along the $x$ direction, and $I$ is the intensity distribution of the sample volume. Detailed mathematical descriptions of this deconvolution procedure using the discrete Fourier transforms to correct for the near-wall distortion have been applied in previous work by Jorgensen and Garbini (1974). In the work by Jorgensen and Garbini (1974), the accuracy of the deconvolution procedure relied on having accurate dimensions of the sample volume shape from acoustic beam characterization tests. The results from their pipe flow measurements showed that as the ratio of the pulse length to the tube diameter $(P L / D)$ decreased to $P L / D<\sim 0.1$, the distortion in the near wall becomes less significant. This is the case for our measurements with the 5-MHz transducer at 2 cycles per pulse where for larger apertures, i.e., $10 \mathrm{~mm}$ and $15 \mathrm{~mm}, P L / D$ is less than 0.1 , and for the 5-mm aperture, $P L / D$ is $\sim 0.12$. Therefore, for the $5-\mathrm{mm}$ aperture where $P L / D>0.1$ is significant, post-measurement wall gate adjustments were carried out while comparing with the reference flow rate values.

For the analysis of measured velocity profiles, we show dimensionless plots where the velocity profile $V_{z}$ is scaled by the maximum measured axial velocity $V_{z} \max ,\left(V_{z} /\right.$ $\left.V_{z} \max \right)$, and the aperture distance from center to the wall $z$ is scaled by half the aperture $B,(z / B)$ (Fig. 6).

The normalized velocity profiles highlight the expected plug-flow region together with wall slip. The wall slip velocity as a ratio of the maximum measured axial velocity was in the range $\sim 0.2-0.4$. For all flow conditions, the velocity profiles show a slight change in the shape from the measurement closest to the disks' center (at $116 \mathrm{~mm}$ ) to the furthest measurement at a radial distance of $396 \mathrm{~mm}$. The velocity profiles especially at $116 \mathrm{~mm}$ show a less distinct flat plug region compared to the rest of the velocity profiles, suggesting that there is some increase in the plug region due to the entrance effect even after $116 \mathrm{~mm}$ from the center. However, the rest of the profiles at 40-mm intervals seem to overlap more, showing a rapid transition to developed plug flow due to the logarithmic pressure decrease that is expected for radial flow (Savage 1964; Dai and Byron Bird 1981). The slight increase in the plug region is more noticeable in measurements carried out within the largest aperture $(15 \mathrm{~mm})$, where a longer development length is expected.
Fig. 5 Carbopol $0.1 \mathrm{wt} \%$ for radial flow within a 15 -mm aperture at $\sim 281 / \mathrm{min}$ and at a radial location of $316 \mathrm{~mm}$. a Velocity profile spectral image. b Mean velocity profile ( 255 profiles averaged) with velocity standard deviation as error bars a

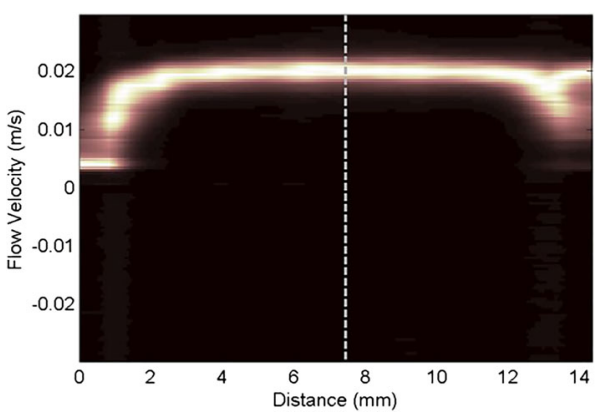

b

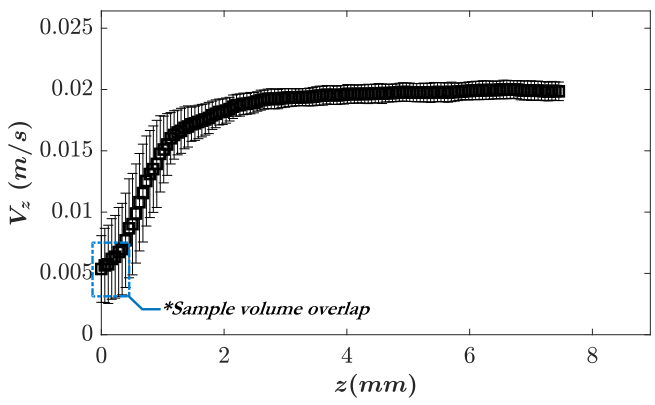




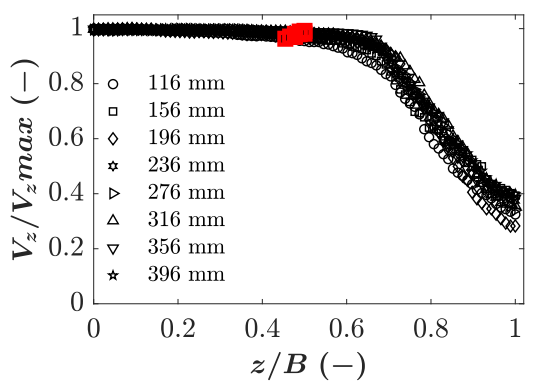

b

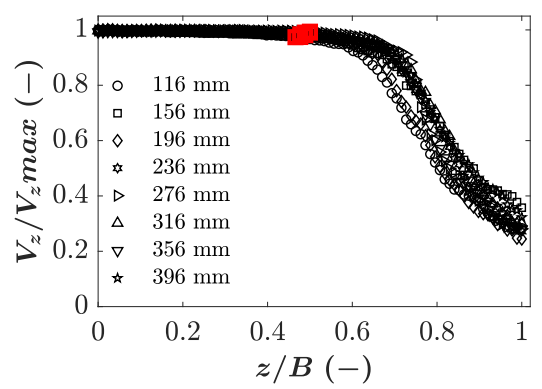

C

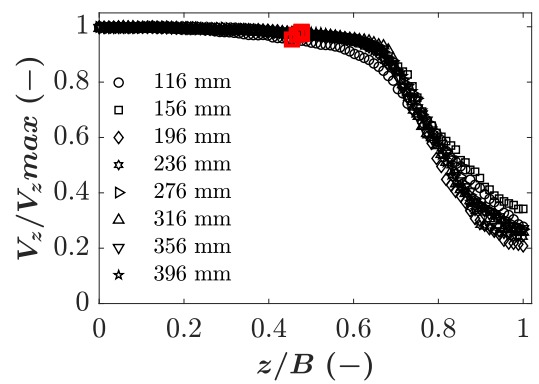

d

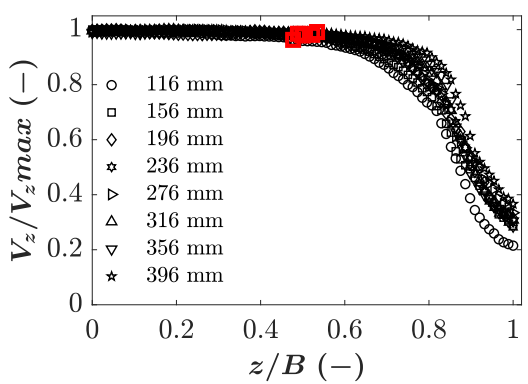

e

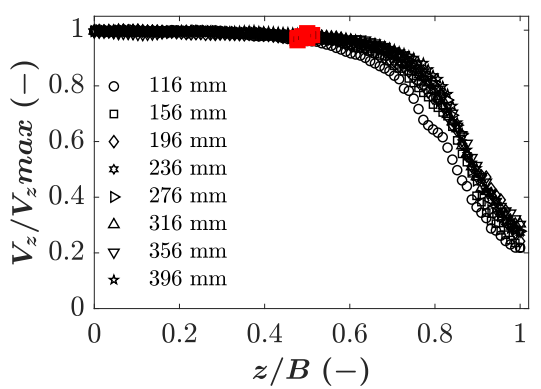

$\mathbf{f}$

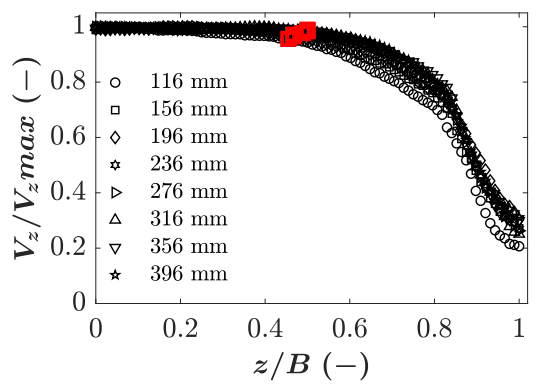

g

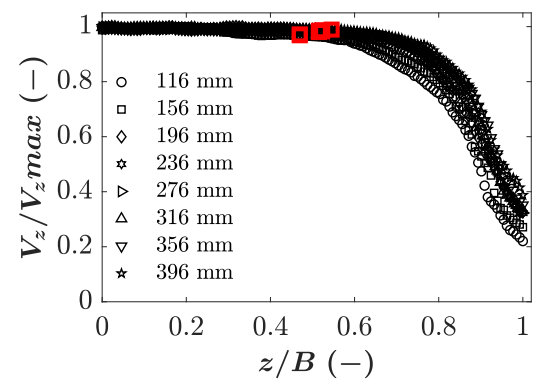

h

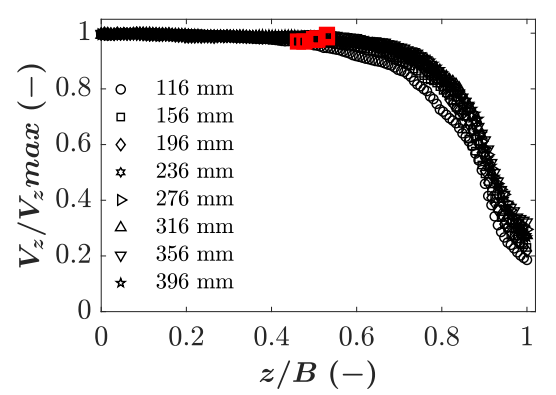

i

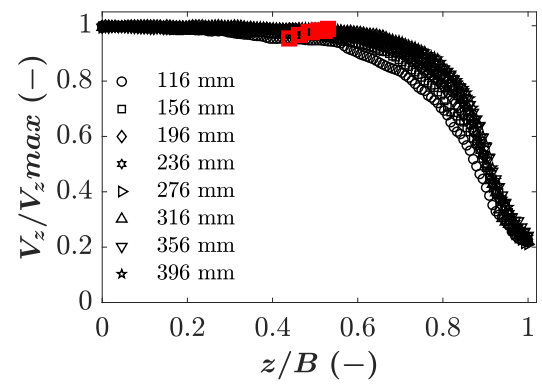

Fig. 6 Dimensionless velocity profiles scaled by the maximum velocity and half-aperture. Graphs for different flow conditions: 5-mm aperture a $\sim 28 \mathrm{l} / \mathrm{min}, \mathbf{b} \sim 40 \mathrm{l} / \mathrm{min}$, and $\mathbf{c} \sim 58 \mathrm{l} / \mathrm{min} ; 10-\mathrm{mm}$ aperture $\mathbf{d} \sim 28 \mathrm{l} / \mathrm{min}$, e $\sim 40 \mathrm{l} / \mathrm{min}$, and $\mathbf{f} \sim 58 \mathrm{l} / \mathrm{min} ; 15-\mathrm{mm}$ aperture $\mathbf{g} \sim 28 \mathrm{l} / \mathrm{min}, \mathbf{h} \sim 40 \mathrm{l} / \mathrm{min}$, and $\mathbf{i} \sim 58 \mathrm{l} / \mathrm{min}$. The red squares are plug positions

For all the measurements, the slip velocity as a ratio of the maximum velocity varied between $(\sim 0.2-0.4)$, which corresponds to as low as $\sim 0.005 \mathrm{~m} / \mathrm{s}$ measured in the $15-\mathrm{mm}$ gap at the lowest flow rate $(\sim 28 \mathrm{l} / \mathrm{min})$ and furthest radial distance (406 mm) to a maximum of $\sim 0.062 \mathrm{~m} / \mathrm{s}$ in the $5-\mathrm{mm}$ gap at the highest flow rate $(\sim 58 \mathrm{l} / \mathrm{min})$ and closest radial distance $(116 \mathrm{~mm})$ to the entrance. Most probably due to slip, the extent of the sheared region is reduced, and a more pronounced plug region is observed in the measurements, compared to the theoretically predicted profiles. Based on the CUSUM plug calculation, the normalized plug region $z_{p} / B$ for all measurements was within the range $\sim(0.45$ to 0.55$)$, whereas $z_{p} / B$ from the constant flow rate prediction for the 3 different flow rates $([\mathrm{Q} 1, \mathrm{Q} 2, \mathrm{Q} 3])$ and apertures with increasing order were: for the 5 -mm aperture, at $z_{p} / B=[0.10 ; 0.09$; $0.08], 10-\mathrm{mm}$ aperture $z_{p} / B=[0.17 ; 0.15 ; 0.13]$; and $15-\mathrm{mm}$ aperture $z_{p} / B=[0.21 ; 0.19 ; 0.17]$. Additionally, we show the variation in the plug ratios along the radial length for each law for the fitted velocity profiles is 0.0013 . 
a

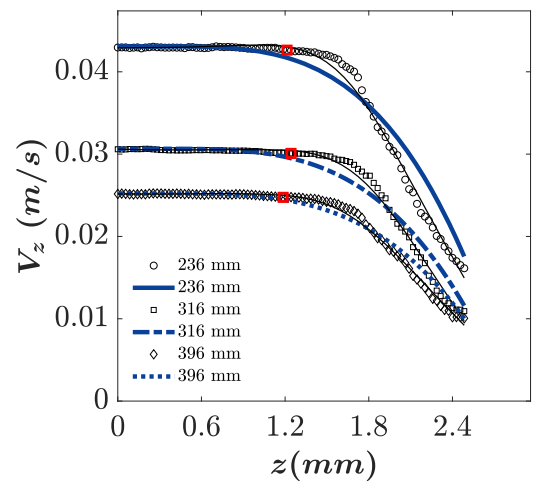

b

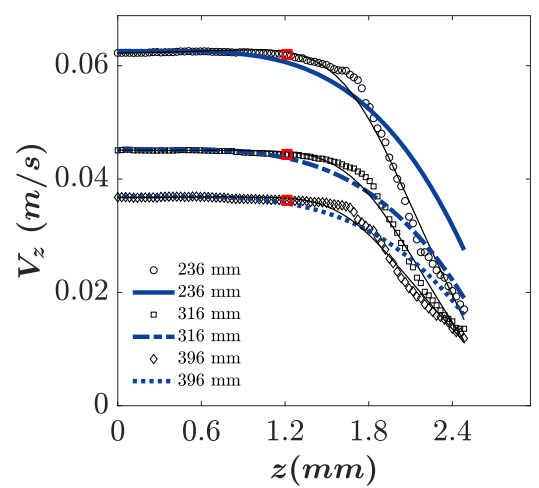

C

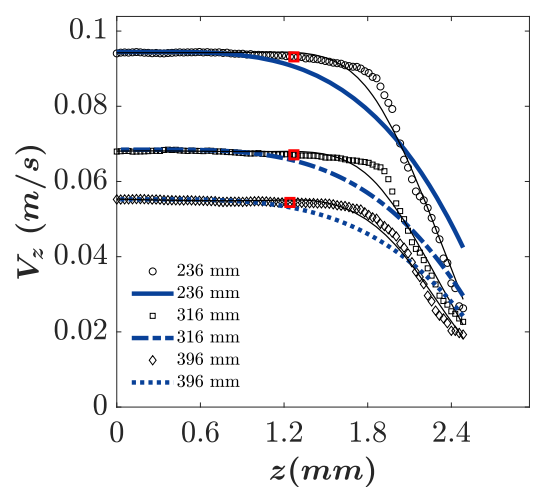

Fig. 7 Measured velocity profiles (circles) and predicted velocity profiles (thick blue lines, dashed and non-dashed) from the constant flow rate solution (Appendix 1, (Zou et al. 2020)) at radial positions $\left(r_{L}=236\right.$; 316; 396) $\mathrm{mm}$. Graphs for different flow conditions. 5-mm aperture a $28 \mathrm{l} / \mathrm{min}, \mathbf{b} \sim 40 \mathrm{l} / \mathrm{min}$, and $\mathbf{c} \sim 58 \mathrm{l} / \mathrm{min} ; 10-\mathrm{mm}$ aperture $\mathbf{d} \sim 28 \mathrm{l} / \mathrm{min}, \mathbf{e} \sim$

flow condition by the box plots (Fig. 8). Like the theoretical prediction, the plug ratios from the measurements per aperture decrease with increasing flow rate; and the values for the ratio $z_{p} / B$ are the highest for the largest aperture and the lowest in the smallest aperture.

The shear rates $\frac{d V_{z}}{d z}$ calculated by differentiating the velocity profiles across the aperture ranged from as low as $\sim(0.01$ to 7$)$ $1 / \mathrm{s}$ in the $15-\mathrm{mm}$ aperture, at $28 \mathrm{1} / \mathrm{min}$ and furthest radial g

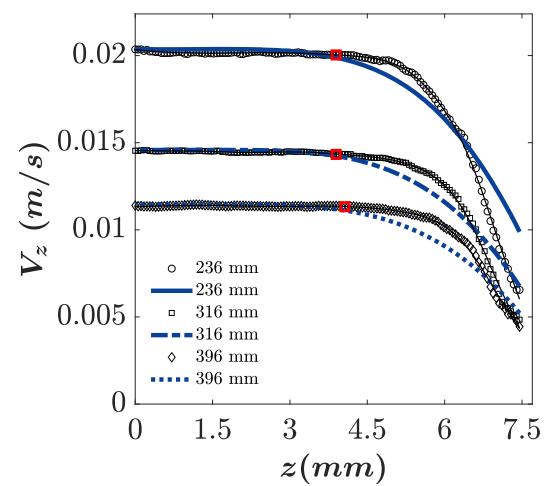

h

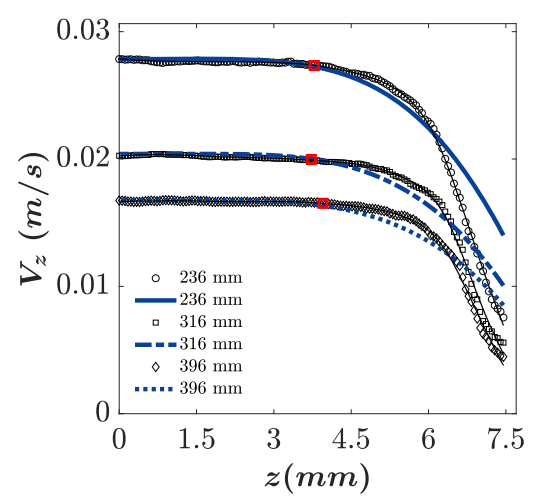

i

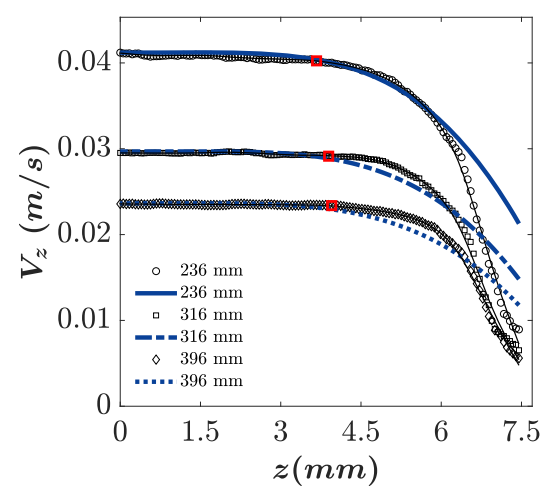

$40 \mathrm{l} / \mathrm{min}$, and $\mathbf{f} \sim 58 \mathrm{l} / \mathrm{min} ; 15-\mathrm{mm}$ aperture $\mathbf{g} \sim 28 \mathrm{l} / \mathrm{min}, \mathbf{h} \sim 40 \mathrm{l} / \mathrm{min}$, and i $\sim 58 \mathrm{l} / \mathrm{min}$. The thin solid lines following the measured data are the smoothing splines used in the calculation of the plug positions (red squares)

location of $406 \mathrm{~mm}$, to a maximum of $\sim 160 \mathrm{1} / \mathrm{s}$ for the velocity profiles within the $5-\mathrm{mm}$ aperture, at $58 \mathrm{1} / \mathrm{min}$ and at a radial location of $116 \mathrm{~mm}$.

\section{Visualization of radial flow and plug region}

To further visualize the radial flow (i.e., velocity distribution and plug region), we also present contour colormaps based on 
Fig. 8 Box plots showing spread in measured plug ratios for each test condition based on the CUSUM plug detection, with red crosses as outliers (outliers $>1.5$ the Inter Quartile Range(IQR))

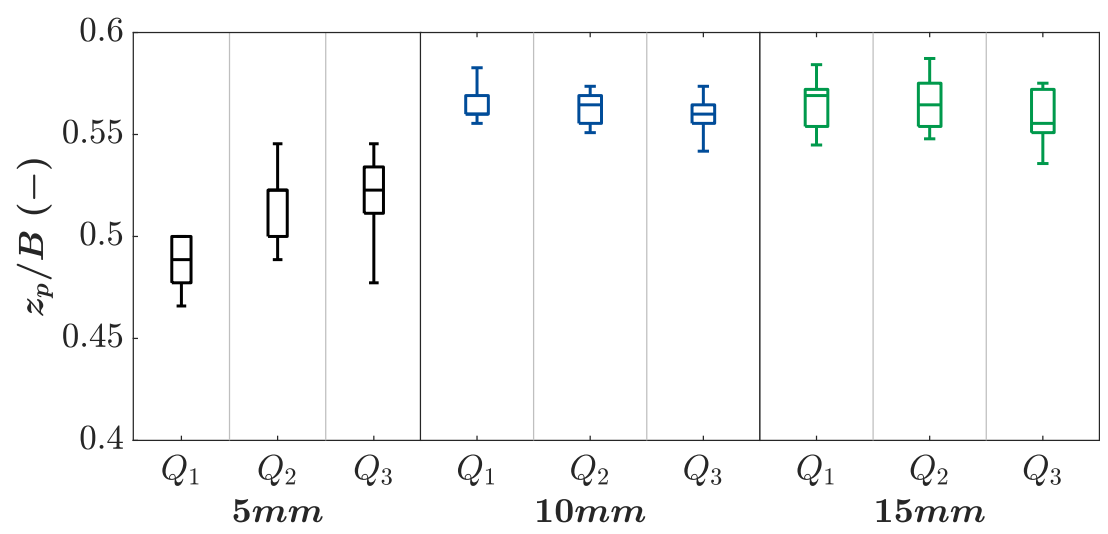

the measured radial velocity profiles. For the velocity contour maps, all velocity profiles measured along the radial length (17 profiles from $116 \mathrm{~mm}$ to $406 \mathrm{~mm}$ ) for a particular flow rate and aperture were plotted in series and then linearly interpolated (Fig. 9).
As expected, the colormaps show high velocities (red area especially in the radial location $\sim\left(116 \leq r_{L} \leq 225 \mathrm{~mm}\right)$, followed by a rapid decrease in velocity magnitude with increasing radial distance. The dark blue area, close to the measurement wall where the ultrasound sensor was placed, is an area of a

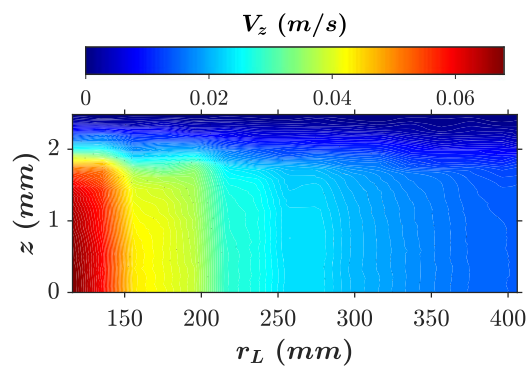

b

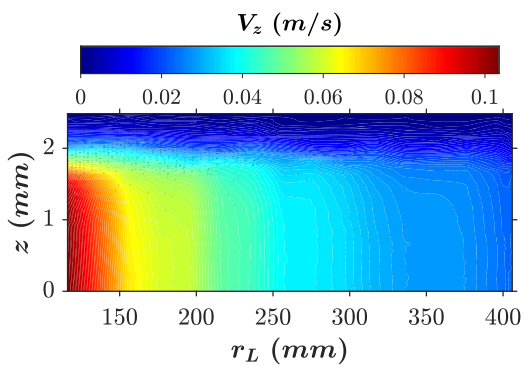

C

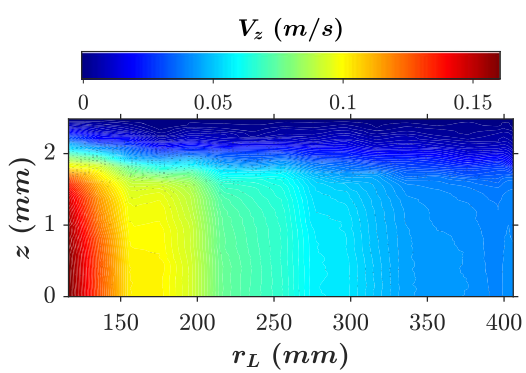

d

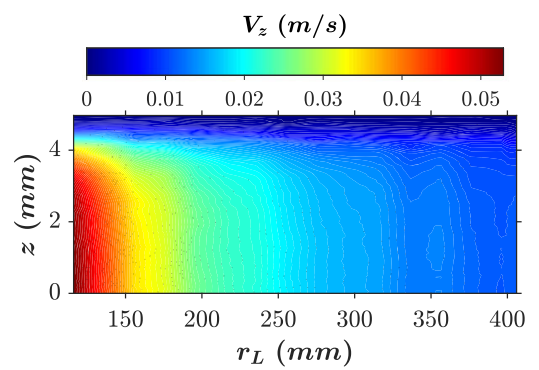

e

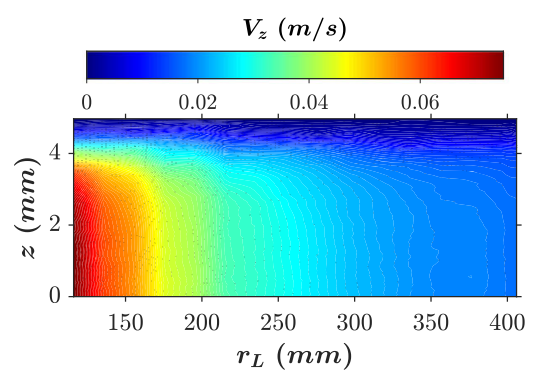

f

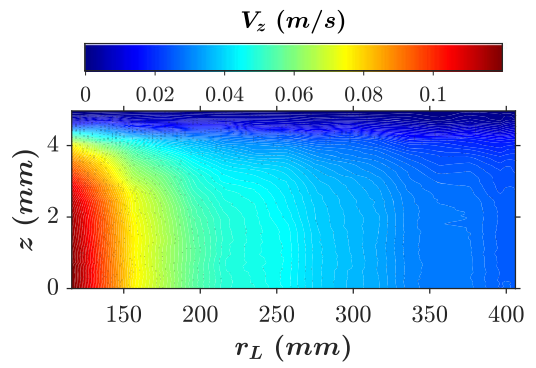

g

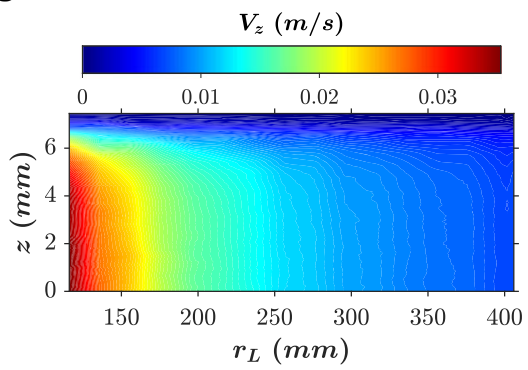

h

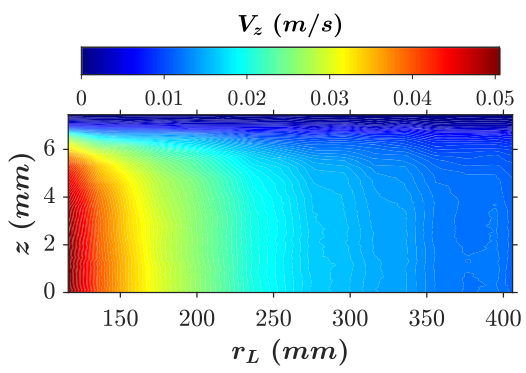

i

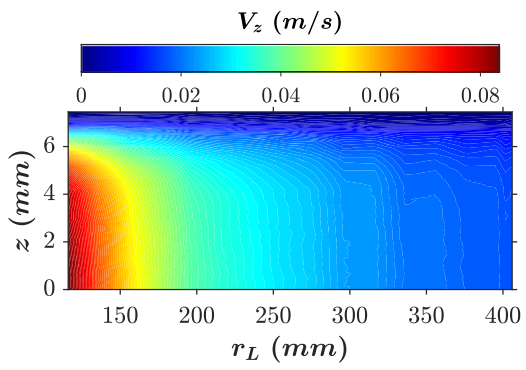

Fig. 9 Contour colormaps of the radial velocity profiles for different apertures and flow rates. 5-mm aperture a $\sim 281 / \mathrm{min}, \mathbf{b} 401 / \mathrm{min}$, and $\mathbf{c} \sim 58 \mathrm{l} / \mathrm{min}$, 10-mm aperture $\mathbf{d} \sim 28 \mathrm{l} / \mathrm{min}, \mathbf{e} \sim 40 \mathrm{l} / \mathrm{min}$, and $\mathbf{f} \sim 58 \mathrm{l} / \mathrm{min}$, and $15-\mathrm{mm}$ aperture $\mathbf{g} \sim 28 \mathrm{l} / \mathrm{min}, \mathbf{h} \sim 40 \mathrm{l} / \mathrm{min}$, and $\mathbf{i} \sim 58 \mathrm{l} / \mathrm{min}$ 
lower velocities compared to the bulk of the flow. This indicates the lower velocities in the sheared region compared to the bulk, where a plug-flow region exists.

\section{Discussion}

In this paper, we presented experimental work carried out to study radial flow velocity profiles of a simple yield stress fluid (YSF), namely, Carbopol 980. The objectives of the work were to design a radial flow model and measure velocity profiles of Carbopol between smooth parallel disks, for apparently the first time, using the ultrasound velocity profiling (UVP) method, with emphasis on the existence of a distinct plug-flow region and the associated slip effects. The pulsed ultrasound beam of the $5 \mathrm{MHz}$ ultrasound sensor used was acoustically characterized using a needle hydrophone setup to determine the Doppler angle that is critical for velocimetry (Shamu et al. 2016). The velocity profile measurements were then carried out for three different apertures $(5 \mathrm{~mm}, 10 \mathrm{~mm}$, and $15 \mathrm{~mm}$ ) and at three different flow rates of $\sim 28 \mathrm{l} / \mathrm{min}, \sim 40 \mathrm{l} / \mathrm{min}$, and $\sim 58 \mathrm{l} / \mathrm{min}$, by positioning the sensor at different locations using a motorized linear axis. For each test condition, i.e., constant flow rate and aperture, 17 different profiles are acquired within the radial length $(116 \mathrm{~mm}$ to $406 \mathrm{~mm}$ from the central injection point).

Different slip mechanisms for polymeric fluids, e.g., Carbopol, have been discussed in the literature (Denn 2001; Aktas and Kalyon 2014; Bonn et al. 2017), and we assume that one or more similar mechanisms are responsible for the observed slip in our measurements (finite wall velocities). Specifically, the mechanism of slip whereby a micron-sized thin water-based film in the vicinity of the wall surrounds the bulk homogenous YSF resulting in less shear deformation within the bulk and hence the flatter "plug-like" velocity profile. This also agrees with our observations where a more distinct plug-flow region, larger than that predicted by the analytical solution, is observed for all velocity profiles. To account for slip in our measurements, we have considered the Navier slip law (Damianou and Georgiou 2014; Kim 2019) (Appendix 1).

In this study, the measured velocity profiles are compared to those predicted by an analytical solution for radial flow of yield-power-law fluids, i.e., Herschel-Bulkley model (Fig. 3) (Zou et al. 2020). A reasonably good agreement is observed in the magnitude of the measured velocity profiles with those from the analytical solution that includes the Navier slip term. The discrepancies in the overall shape of the profiles may be caused by the much longer development length required especially in the larger $15-\mathrm{mm}$ aperture and significant aperture increases especially in the 5-mm aperture. On the same point, we mention that the theoretical prediction for radial flow is based on simplifications (lubrication assumption) that might be valid only for relatively smaller apertures compared to radial lengths. Moreover, according to earlier studies on radial flow experiments with Carbopol by Laurencena and Williams (1974), there might be secondary flow velocity components associated to elastic effects that can influence the overall flow dynamics, which is also expected for the Carbopol polymeric fluid. However, such secondary flow effects and other types of wall slip conditions need to be systematically studied in the future.

We present an effective method to quantify the plug-flow region using a CUSUM-based algorithm to detect the point at which the mean velocity within the plug region decreases from a nearly constant mean value, tending towards the sheared region with lower velocities ("Method for determining plug region"). The detected plug region is shown to be within the range $z / B=\sim 0.45$ to 0.55 (Figs. 6, 8, 9). Additionally, contour colormaps plotted from the radial velocity profiles show the existence of this plug, which also extends a similar length of the half-aperture as calculated from the CUSUM method. Some limitations inherent in the CUSUM method of plug region detection ("Velocity profile measurements") are mainly due to fluctuations within the measurement velocity data and the consequent spline fitting.

Some uncertainties associated to correct detection of the wall position need to be considered for the next study to improve the overall accuracy of the measurements. The accuracy of the measured data (spatial resolution) can be further improved by using a higher frequency transducer (e.g., $8 \mathrm{MHz}$ ), different piezo crystal and number of pulse cycles; however our current measurements with the UVP technique using a $5 \mathrm{MHz}$ sensor have shown the shape of the velocity profiles in radial flow, with sufficient detail, i.e., velocity points across the aperture. For future tests, we plan to improve our current flow model by introducing roughened plexiglass disks to reduce slip effects, and improve the ultrasound sensor resolution and wall detection algorithm. Also, an adjustment to the placement of the magnetic flow meter closer to the inlet pipe would improve the overall volumetric flow rate comparisons. Consequently, we could then systematically measure the radial flow profiles of Carbopol to determine the shape of the plug-flow region in detail, which remains a challenging issue for studies on fluids that exhibit a yield stress and engineering applications such as rock grouting design.

\section{Conclusions}

The main conclusions drawn from this work are summarized as follows:

- The radial flow model developed in this study combined with the UVP system for velocimetry can be successfully 
applied to the direct measurement of velocity profiles for studying radial flow of yield stress fluids (YSF); such experimental measurements have not been presented earlier in the literature.

- Although there was some slight uncertainty in the wall position especially for the smaller aperture, the $5-\mathrm{MHz}$ ultrasound sensors used together with the Incipientus UVP system are capable of carrying out detailed noninvasive velocimetry measurements through plexiglass $(\sim$ $5 \mathrm{~mm}$ wall thickness).

- Carbopol as a simple YSF can be used to study complex flows, e.g., radial flow of yield-power-law fluids as shown in this paper. A preparation procedure for Carbopol gels ensuring little to no rheological hysteresis even after the addition of ultrasound reflector particles is described in detail.

- The plug-flow region determination method based on the CUSUM algorithm is an effective approach that can be used to identify the plug-flow region in detail. The effectiveness of the algorithm was seen in the consistent determination of the plug positions for similar profiles; also the profiles near the entrance, e.g., at $116 \mathrm{~mm}$ were correctly assessed as having a slightly smaller plug region compared to the other profiles measured under the same flow conditions ("Velocity profile measurements").

- For future work, different algorithms based on the modified CUSUM method or similar may be developed for improved plug detection. The accuracy of the algorithm presented in this paper depends on the initial estimates, e.g., the approximate extent of plug region and also the local fluctuations in the data itself ("Method for determining plug region").

- There could have been some slight aperture increase in the 5-mm gap due to higher pressure buildup; this issue needs to be looked at closely and addressed as part of the next study.

Other important issues that still need to be addressed are the detection of the wall positions especially in flows where significant wall slip effects result in finite wall velocities. The wall uncertainty is mainly due to the overlapping sample volume at the fluid-wall interface, and possibly the coupled effect of wall slip. As mentioned in the discussion, the use of higher frequency ultrasound sensors may be used to reduce this uncertainty by providing higher axial and lateral resolution so that the wall location is more evident.

Acknowledgments Michal Kotzé at Incipientus AB is acknowledged for his assistance with the acoustic characterization test setup.

Funding information Open access funding provided by Royal Institute of Technology. The authors would like to thank the Development Fund of the Swedish Construction Industry (SBUF) and the Rock Engineering Research Foundation $(\mathrm{BeFo})$ for funding this work.

\section{Appendix 1}

\section{Analytical solution for yield-power-law- fluids radial flow between parallel disks (Zou et al. 2020)}

Based on the assumption of lubrication approximation, the analytical of velocity profiles for incompressible yieldpower-law fluids, steady-state, laminar, and radial flow between parallel disks can be expressed as:

$$
\begin{aligned}
& v_{z}^{f}\left(z_{p}<z \leq B\right) \\
& =\frac{n}{n+1}\left(-\frac{1}{k} \frac{\partial P}{\partial r}\right)^{\frac{1}{n}}\left[\left(B-z_{p}\right)^{\frac{n+1}{n}}-\left(z-z_{p}\right)^{\frac{n+1}{n}}\right] \\
& v_{z}^{p}\left(0 \leq z<z_{p}\right)=\frac{n}{n+1}\left(-\frac{1}{k} \frac{\partial P}{\partial r}\right)^{\frac{1}{n}}\left(B-z_{p}\right)^{\frac{n+1}{n}}
\end{aligned}
$$

where $v_{z}^{f}$ is the velocity for the yielding flow parts between the edges of plug-flow region $\left(z_{p}\right)$ and the walls $(B), v_{z}^{p}$ is the velocity for the plug-flow region, $\frac{\partial P}{\partial r}$ is the pressure gradient, $r$ and $z$ are the radial and vertical coordinates, $k$ is the consistency coefficient, $n$ is the flow index, and $z_{p}$ is the half of the plug-flow region, expressed as

$z_{p}=\frac{\tau_{0}\left(r_{t}-r_{0}\right)}{\left(P_{1}-P_{2}\right)}$

where $\tau_{0}$ is the yield stress and $P_{1}$ and $P_{2}$ are the pressure at the inlet $r_{0}$ and outlet $r_{t}$. The pressure gradient is expressed as

$\frac{\partial P}{\partial r}=-\frac{1}{r} \frac{P_{1}-P_{2}}{\ln \left(\frac{r_{t}}{r_{0}}\right)}$

The flow rate $Q$ is obtained by integration of the velocity over the aperture, written as

$$
\begin{aligned}
Q & =\int_{0}^{B} 4 \pi r v_{z} d z \\
& =\frac{4 \pi r n}{n+1}\left(-\frac{1}{k} \frac{\partial P}{\partial r}\right)^{\frac{1}{n}} B^{\frac{2 n+1}{n}}\left(1-\frac{z_{p}}{B}\right)^{\frac{n+1}{n}}\left[1-\frac{n}{2 n+1}\left(1-\frac{z_{p}}{B}\right)\right]
\end{aligned}
$$

Wall slip is observed in our tests as shown in Figs. 5, 6, and 7. In this work, we consider the linear Navier slip law as described by Ferrás et al. (2012), Damianou and Georgiou (2014), Damianou et al. (2016), and Kim (2019) on the walls, where the wall slip velocity, $v_{w}$, is proportional to the wall shear stress, expressed as,

$v_{w}=\beta \tau_{w}$

where $\tau_{w}$ is the wall shear stress and $\beta$ is the slip coefficient. The analytical solution of the velocity profile can then be written as 


$$
\begin{aligned}
v_{z}^{f}\left(z_{p}<z \leq B\right)= & \frac{n}{n+1}\left(-\frac{1}{k} \frac{\partial \mathrm{P}}{\partial r}\right)^{\frac{1}{n}}\left[\left(B-z_{p}\right)^{\frac{n+1}{n}}-\left(z-z_{p}\right)^{\frac{n+1}{n}}\right] \\
& +\beta\left[\tau_{0}-\frac{\partial P}{\partial r}\left(B-z_{p}\right)\right] \\
v_{z}^{p}\left(0 \leq z<z_{p}\right)= & \frac{n}{n+1}\left(-\frac{1}{k} \frac{\partial P}{\partial r}\right)^{\frac{1}{n}}\left(B-z_{p}\right)^{\frac{n+1}{n}} \\
& +\beta\left[\tau_{0}-\frac{\partial P}{\partial r}\left(B-z_{p}\right)\right]
\end{aligned}
$$

The flow rate $Q$ with consideration of Navier slip condition is

$$
\begin{aligned}
Q= & \int_{0}^{B} 4 \pi r v_{z} d z \\
= & \frac{4 \pi r n}{n+1}\left(-\frac{1}{k} \frac{\partial P}{\partial r}\right)^{\frac{1}{n}} B^{\frac{2 n+1}{n}}\left(1-\frac{z_{p}}{B}\right)^{\frac{n+1}{n}}\left[1-\frac{n}{2 n+1}\left(1-\frac{z_{p}}{B}\right)\right] \\
& +4 \pi r B \beta\left[\tau_{0}-\frac{\partial P}{\partial r}\left(B-z_{p}\right)\right]
\end{aligned}
$$

\section{Appendix 2}

\section{Adjustment of aperture deflection}

Due to the upward pressure applied to the Plexiglass disks as the Carbopol gel flows in the radial direction there is some deflection that results in an increased mean aperture, $2 B^{*}$ that is greater than the nominal values, i.e., $5 \mathrm{~mm}$, $10 \mathrm{~mm}$, and $15 \mathrm{~mm}$. Here $2 B^{*}$ is the deflection $\delta b$ plus the initial nominal aperture, $2 B$. The magnitudes of the deflection $\delta b$ were estimated by performing a stress analysis on the finite element model (FEM) of the radial flow model that was used for manufacturing and asssembly. The FEM model and stress analysis were carried out in the Autodesk Inventor ${ }^{\circledR}$ simulation environment while using the same components and materials that were used to manufacture the physical model. For the simulation the stainless steel frames were assigned mechanical properties of stainless steel 316 and for the plexiglass disks, PolyMethyl Methacrylate (PMMA), Plexiglas $®$ properties.

Absolute pressure values that were measured on the vertical pipe inlet into the radial flow area were used as input during to the stress analysis. The point pressure measurements used as estimates of the maximum uplift pressures in the FEM model were measured by an absolute pressure sensor in the physical radial model. The location of the pressure sensor was at a vertical height of $275 \mathrm{~mm}$ along the injection pipe $(20-\mathrm{mm}$ inner diameter into the radial flow area). Figure 2 a shows the $3 \mathrm{D}$ CAD model used in the FEM simulation. A summary of the adjusted apertures that were used in the analytical predictions for comparison with the measured velocity profiles are summarized in Table 2.
Table 2 Estimated total deflection of bottom and top plexiglass disks

\begin{tabular}{lllll}
\hline $\begin{array}{l}\text { Maximum uplift from absolute } \\
\text { pressure, }(\mathrm{kPa})\end{array}$ & $\begin{array}{l}\text { Flow rate, } \mathrm{Q} \\
(1 / \mathrm{min})\end{array}$ & $\begin{array}{l}\text { Nominal aperture, } \\
2 B(\mathrm{~mm})\end{array}$ & $\begin{array}{l}\text { Deflection, } \\
\delta b,(\mathrm{~mm})\end{array}$ & $\begin{array}{l}\text { Adjusted aperture, } \\
2 B^{*}, \mathrm{~mm}\end{array}$ \\
\hline 10.98 & 28 & 5 & 0.92 & 5.92 \\
12.34 & 40 & 5 & 1.02 & 6.02 \\
12.97 & 58 & 5 & 1.08 & 6.08 \\
5.61 & 28 & 10 & 0.47 & 10.47 \\
6.98 & 40 & 10 & 0.58 & 10.58 \\
7.78 & 58 & 10 & 0.64 & 10.64 \\
4.98 & 28 & 15 & 0.41 & 15.41 \\
5.70 & 40 & 15 & 0.47 & 15.47 \\
6.18 & 58 & 15 & 0.50 & 15.50 \\
\hline
\end{tabular}


Open Access This article is licensed under a Creative Commons Attribution 4.0 International License, which permits use, sharing, adaptation, distribution and reproduction in any medium or format, as long as you give appropriate credit to the original author(s) and the source, provide a link to the Creative Commons licence, and indicate if changes were made. The images or other third party material in this article are included in the article's Creative Commons licence, unless indicated otherwise in a credit line to the material. If material is not included in the article's Creative Commons licence and your intended use is not permitted by statutory regulation or exceeds the permitted use, you will need to obtain permission directly from the copyright holder. To view a copy of this licence, visit http://creativecommons.org/licenses/by/4.0/.

\section{References}

Aktas S, Kalyon DM (2014) Shear viscosity and wall slip behavior of a viscoplastic hydrogel. J Rheol 58:24

Axelsson M, Gustafson G, Fransson Å (2009) Stop mechanism for cementitious grouts at different water-to-cement ratios. Tunn Undergr Space Technol 24:390-397. https://doi.org/10.1016/j.tust.2008.11. 001

Balmforth NJ, Frigaard IA, Ovarlez G (2014) Yielding to stress: recent developments in Viscoplastic fluid mechanics. Annu Rev Fluid Mech 46:121-146. https://doi.org/10.1146/annurev-fluid-010313141424

Barber WD, Eberhard JW, Karr SG (1985) A new time domain technique for velocity measurements using Doppler ultrasound. Biomed Eng IEEE trans on 213-229

Barnes HA, Nguyen QD (2001) Rotating vane rheometry - a review. J Non-Newton Fluid Mech 98:1-14. https://doi.org/10.1016/S03770257(01)00095-7

Berta M, Wiklund J, Kotze R, Stading M (2016) Correlation between inline measurements of tomato ketchup shear viscosity and extensional viscosity. J Food Eng 173:8-14

Birkhofer BH (2007) Ultrasonic in-line characterization of suspensions. Laboratory of Food Process Engineering Institute of food science and nutrition Swiss Federal Institute of technology (ETH) Zurich ETH Zentrum, Zurich

Bonn D, Denn MM, Berthier L et al (2017) Yield Stress Materials in Soft Condensed Matter. Rev Mod Phys 89. https://doi.org/10.1103/ RevModPhys.89.035005

Cheng DC-H (2003) Characterisation of thixotropy revisited. Rheol Acta 42:372-382. https://doi.org/10.1007/s00397-002-0286-3

Chhabra RP, Richardson JF (1999) Chapter 3 - Flow in pipes and in conduits of non-circular cross-sections. In: Non-Newtonian Flow in the Process Industries. Butterworth-Heinemann, pp 73-161. https://doi.org/10.1016/B978-0-7506-3770-1.X5000-3

Coussot P (2014) Yield stress fluid flows: a review of experimental data. J Non-Newton Fluid Mech 211:31-49. https://doi.org/10.1016/j. jnnfm.2014.05.006

Coussot P (2017) Bingham's heritage. Rheol Acta 56:163-176. https:// doi.org/10.1007/s00397-016-0983-y

Coussot P, Tabuteau H, Chateau X et al (2006) Aging and solid or liquid behavior in pastes. J Rheol 50:975-994. https://doi.org/10.1122/1. 2337259

Dai G, Byron Bird R (1981) Radial flow of a Bingham fluid between two fixed circular disks. J Non-Newton Fluid Mech 8:349-355. https:// doi.org/10.1016/0377-0257(81)80031-6

Damianou Y, Georgiou GC (2014) Viscoplastic Poiseuille flow in a rectangular duct with wall slip. J Non-Newton Fluid Mech 214:88-105. https://doi.org/10.1016/j.jnnfm.2014.10.002
Damianou Y, Kaoullas G, Georgiou GC (2016) Cessation of viscoplastic Poiseuille flow in a square duct with wall slip. J Non-Newton Fluid Mech 233:13-26. https://doi.org/10.1016/j.jnnfm.2015.11.002

Denn MM (2001) Extrusion instabilities and wall slip. Annu Rev Fluid Mech 33:265-287. https://doi.org/10.1146/annurev.fluid.33.1.265

Di Giuseppe E, Corbi F, Funiciello F et al (2015) Characterization of Carbopol ${ }^{\circledR}$ hydrogel rheology for experimental tectonics and geodynamics. Tectonophysics 642:29-45. https://doi.org/10.1016/ j.tecto.2014.12.005

Dinkgreve M, Denn MM, Bonn D (2017) “Everything flows?”: elastic effects on startup flows of yield-stress fluids. Rheol Acta 56:189 194. https://doi.org/10.1007/s00397-017-0998-z

Dinkgreve M, Fazilati M, Denn MM, Bonn D (2018) Carbopol: from a simple to a thixotropic yield stress fluid. J Rheol 62:773-780. https://doi.org/10.1122/1.5016034

Divoux T, Barentin C, Manneville S (2011) Stress overshoot in a simple yield stress fluid: an extensive study combining rheology and velocimetry. Soft Matter 7:9335. https://doi.org/10.1039/ c1sm05740e

Divoux T, Fardin MA, Manneville S, Lerouge S (2016) Shear banding of complex fluids. Annu Rev Fluid Mech 48:81-103. https://doi.org/ 10.1146/annurev-fluid-122414-034416

Dogan N, McCarthy MJ, Powell RL (2005) Measurement of polymer melt rheology using ultrasonics-based in-line rheometry. Meas Sci Technol 16:1684-1690. https://doi.org/10.1088/0957-0233/16/8/ 021

Draganović A, Stille H (2014) Filtration of cement-based grouts measured using a long slot. Tunn Undergr Space Technol 43:101-112. https://doi.org/10.1016/j.tust.2014.04.010

El Tani M (2012) Grouting rock fractures with cement grout. Rock Mech Rock Eng 45:547-561. https://doi.org/10.1007/s00603-012-0235-0

Ferrás LL, Nóbrega JM, Pinho FT (2012) Analytical solutions for Newtonian and inelastic non-Newtonian flows with wall slip. J Non-Newton Fluid Mech 175-176:76-88. https://doi.org/10.1016/ j.jnnfm.2012.03.004

Fransson $\AA$ (2001) Characterisation of a fractured rock mass for a grouting field test. Tunn Undergr Space Technol 16:331-339. https://doi.org/10.1016/S0886-7798(01)00060-8

Fransson A, Funehag J, Thörn J (2016) Swedish grouting design: hydraulic testing and grout selection. Proc Inst Civ Eng - Ground Improv 169:275-285. https://doi.org/10.1680/jgrim. 15.00020

Funehag J, Thörn J (2018) Radial penetration of cementitious grout laboratory verification of grout spread in a fracture model. Tunn Undergr Space Technol 72:228-232. https://doi.org/10.1016/j.tust. 2017.11.020

Grigg OA, Farewell VT, Spiegelhalter DJ (2003) Use of risk-adjusted CUSUM and RSPRTcharts for monitoring in medical contexts. Stat Methods Med Res 12:147-170. https://doi.org/10.1177/ 096228020301200205

Guo J, Shan H, Xie Z, et al (2017) Exact solution to navier-stokes equation for developed radial flow between parallel disks. J Eng Mech 143(6):10. https://doi.org/10.1061/(ASCE)EM.1943-7889.0001227

Gustafson G, Stille H (2005) Stop criteria for cement grouting. Felsbau 23:62-68

Gustafson G, Claesson J, Fransson Å (2013) Steering parameters for rock grouting. J Appl Math 2013:1-9

Håkansson U (1993) Rheology of fresh cement-based grouts. Dissertation, Royal Institute of Technology, Stockholm

Håkansson U, Hässler L, Stille H (1992) Rheological properties of microfine cement grouts. Tunn Undergr Space Technol 7:453-458

Hässler L (1991) Grouting of rock - simulation and classification. PhD., Royal Institute of Technology (KTH)

Jorgensen JE, Garbini JL (1974) An analytical procedure of calibration for the pulsed ultrasonic Doppler flow meter. J Fluids Eng 96:10

Kelessidis VC, Hatzistamou V (2011) Preparation methodology and rheological properties of yield Pseudoplastic transparent fluids. J 
Dispers Sci Technol 32:380-388. https://doi.org/10.1080/ 01932691003662399

Kim SK (2019) Flow rate based framework for solving viscoplastic flow with slip. J Non-Newton Fluid Mech 269:37-46. https://doi.org/10. 1016/j.jnnfm.2019.06.002

Kotze R, Wiklund J, Haldenwang R (2012) Optimization of the UVP+ $\mathrm{PD}$ rheometric method for flow behavior monitoring of industrial fluid suspensions. Appl Rheol 22:42760-42761

Laurencena BR, Williams MC (1974) Radial flow of non-Newtonian fluids between parallel plates. Trans Soc Rheol 18:331-355. https://doi.org/10.1122/1.549339

Lipscomb GG, Denn MM (1984) Flow of bingham fluids in complex geometries. J Non-Newton Fluid Mech 14:337-346. https://doi.org/ 10.1016/0377-0257(84)80052-X

Majidi R, Miska SZ, Ahmed R et al (2010) Radial flow of yield-powerlaw fluids: numerical analysis, experimental study and the application for drilling fluid losses in fractured formations. J Pet Sci Eng 70: 334-343. https://doi.org/10.1016/j.petrol.2009.12.005

McCarthy KL, Kerr WL, Kauten RJ, Walton JH (1997) Velocity profiles of fluid/particulate mixtures in pipe flow using MRI. J Food Process Eng 20(2):165-177

Mohammed MH, Pusch R, Knutsson S (2015) Study of cement-grout penetration into fractures under static and oscillatory conditions. Tunn Undergr Sp Tech 45:10-19. https://doi.org/10.1016/j.tust. 2014.08.003

Na TY, Hansen AG (1967) Radial flow of viscous non-Newtonian fluids between disks. Int J Non-Linear Mech 2:261-273. https://doi.org/ 10.1016/0020-7462(67)90027-3

Nejad Ghafar A (2017) An experimental study to measure grout penetrability, improve the grout spread, and evaluate the real time grouting control theory. Dissertation, KTH Royal Institute of Technology, Stockholm

Nguyen QD, Boger DV (1992) Measuring the flow properties of yield stress fluids. Annu Rev Fluid Mech 24:47-88. https://doi.org/10. 1146/annurev.fl.24.010192.000403

Ovarlez G, Hormozi S (2018) Visco-plastic fluids: from theory to application. Springer, Berlin Heidelberg

Ovarlez G, Cohen-Addad S, Krishan K et al (2013) On the existence of a simple yield stress fluid behavior. J Non-Newton Fluid Mech 193: 68-79

Pfund DM, Greenwood MS, Bamberger JA, Pappas RA (2006) Inline ultrasonic rheometry by pulsed Doppler. Ultrasonics 44:e477-e482. https://doi.org/10.1016/j.ultras.2006.05.027

Powell RL (2008) Experimental techniques for multiphase flows. Phys Fluids 20:040605. https://doi.org/10.1063/1.2911023

Rahman M, Wiklund J, Kotzé R, Håkansson U (2017) Yield stress of cement grouts. Tunn Undergr Space Technol 61:50-60. https://doi. org/10.1016/j.tust.2016.09.009

Ricci S, Meacci V (2018) Data-adaptive coherent demodulator for high dynamics pulse-wave ultrasound applications. Electronics 7:434. https://doi.org/10.3390/electronics7120434

Ricci S, Boni E, Guidi F et al (2006) A programmable real-time system for development and test of new ultrasound investigation methods.
IEEE Trans Ultrason Ferroelectr Freq Control 53:1813-1819. https://doi.org/10.1109/TUFFC.2006.113

Ricci S, Birkhofer B, Lootens D, Tortoli P (2010) In-line rheometry for highly filled suspensions through Doppler ultrasound. In: Ultrasonics symposium (IUS), 2010 IEEE. IEEE, pp 2044-2047

Ricci S, Liard M, Birkhofer B et al (2012) Embedded Doppler system for industrial in-line rheometry. Ultrason Ferroelectr Freq Control IEEE Trans On 59:1395-1401

Ricci S, Meacci V, Birkhofer B, Wiklund J (2017) FPGA-based system for in-line measurement of velocity profiles of fluids in industrial pipe flow. IEEE Trans Ind Electron 64:3997-4005. https://doi.org/ 10.1109/TIE.2016.2645503

Roberts GP, Barnes HA (2001) New measurements of the flow-curves for Carbopol dispersions without slip artefacts. Rheol Acta 40:499-503

Savage SB (1964) Laminar radial flow between parallel plates. J Appl Mech 31:594. https://doi.org/10.1115/1.3629719

Shamu TJ, Kotze R, Wiklund J (2016) Characterization of acoustic beam propagation through high-grade stainless steel pipes for improved pulsed ultrasound Velocimetry measurements in complex industrial fluids. IEEE Sensors J 16:5636-5647. https://doi.org/10.1109/ JSEN.2016.2569491

Stille H (2015) Rock grouting - theories and applications. Vulkanmedia, Stockholm

Takeda Y (1999) Ultrasonic Doppler method for velocity profile measurement in fluid dynamics and fluid engineering. Exp Fluids 26: $177-178$

Takeda Y (2012) Ultrasonic Doppler velocity profiler for fluid flow. Springer, Tokyo

Wallner M (1977) Propagation of sedimentation stable cement pastes in jointed rock : Wallner, M Publ Inst Found Engng, Soil Mech, Rock Mech, Waterways Constr, Aachen, V2, 1976, P49-165. Int J Rock Mech Min Sci Geomech Abstr 14:14

Wiklund J, Shahram I, Stading M (2007) Methodology for in-line rheology by ultrasound Doppler velocity profiling and pressure difference techniques. Chem Eng Sci 62:4277-4293. https://doi.org/10.1016/j. ces.2007.05.007

Wunderlich T, Brunn PO (1999) Ultrasound pulse Doppler method as a viscometer for process monitoring. Flow Meas Instrum 10:201-205. https://doi.org/10.1016/S0955-5986(99)00016-3

Zou L, Håkansson U, Cvetkovic V (2018) Two-phase cement grout propagation in homogeneous water-saturated rock fractures. Int J Rock Mech Min Sci 106:243-249. https://doi.org/10.1016/j.ijrmms.2018. 04.017

Zou L, Håkansson U, Cvetkovic V (2019) Cement grout propagation in two-dimensional fracture networks: impact of structure and hydraulic variability. Int J Rock Mech Min Sci 115:1-10. https://doi.org/10. 1016/j.jirmms.2019.01.004

Zou L, Håkansson U, Cvetkovic V (2020) Radial propagation of yieldpower-law grouts into water-saturated homogeneous fractures. Manuscript submitted for publication.

Publisher's note Springer Nature remains neutral with regard to jurisdictional claims in published maps and institutional affiliations. 